\title{
Article \\ First Description of the Female of the Trinidadian Theraphosine Spinosatibiapalpus trinitatis (Pocock, 1903) (Araneae: Theraphosidae) $^{\dagger}$
}

\author{
Danniella Sherwood $^{1, *}$, José Paulo Leite Guadanucci ${ }^{2}$ and Ray Gabriel ${ }^{1}$ \\ 1 Arachnology Research Association, UK; angelarachnid@gmail.com \\ 2 Departamento de Biodiversidade, Universidade Estadual Paulista, Rio Claro 13506-900, Brazil; \\ joseguadanucci@gmail.com \\ * Correspondence: danni.sherwood@hotmail.com \\ † urn:lsid:nmbe.ch:spidersp:002215.
}

check for updates

Citation: Sherwood, D.; Guadanucci, J.P.L.; Gabriel, R. First Description of the Female of the Trinidadian Theraphosine Spinosatibiapalpus trinitatis (Pocock, 1903) (Araneae: Theraphosidae). Taxonomy 2022, 2, 41-47. https://doi.org/10.3390/ taxonomy2010003

Academic Editor: Volker W. Framenau

Received: 3 December 2021

Accepted: 29 December 2021

Published: 30 December 2021

Publisher's Note: MDPI stays neutral with regard to jurisdictional claims in published maps and institutional affiliations.

Copyright: (c) 2021 by the authors Licensee MDPI, Basel, Switzerland. This article is an open access article distributed under the terms and conditions of the Creative Commons Attribution (CC BY) license (https:// creativecommons.org/licenses/by/ $4.0 /)$.

\begin{abstract}
The hitherto unknown female of the theraphosine Spinosatibiapalpus trinitatis (Pocock, 1903) is herein described based on the paralectotype series of the schismatotheline Neoholothele incei (F. O. Pickard-Cambridge, 1899) housed in the collections of the Natural History Museum, London.
\end{abstract}

Keywords: taxonomy; morphology; museums; spermathecae; tarantula

\section{Introduction}

The genus Spinosatibiapalpus Gabriel \& Sherwood, 2020 currently contains four species recognised by version 22.5 of the World Spider Catalog [1] namely: Spinosatibiapalpus bora Sherwood \& Gabriel, 2021 [2], Spinosatibiapalpus spinulopalpus (Schmidt \& Weinmann, 1997) [3], Spinosatibiapalpus tansleyi Gabriel \& Sherwood, 2020 [4] and Spinosatibiapalpus trinitatis (Pocock, 1903) [5].

Originally described as Metriopelma trinitatis Pocock, 1903, S. trinitatis was based on a single male collected with the location of simply "Trinidad" [5] (p. 114). Subsequently, in 1911, Petrunkevitch [6] considered this species to belong to the genus Crypsidromus Ausserer, 1871 [7], following Simon [8] who had considered Crypsidromus synonymous with Metriopelma Becker, 1878 [9] in 1892. Strand [10] described a subspecies, Crypsidromus trinitatis pauciaculeis Strand, 1916, based on a single male, also from the general locality of "Trinidad" [10] (p. 84). One hundred years later, Gabriel [11], in his revision of Metriopelma (alongside other genera), tentatively transferred both $C$. trinitatis and $C$. trinitatis pauciaculeis to Pseudhapalopus Strand, 1907 [12] where they remained until the redescription and transfer of $P$. trinitatis to the newly described Spinosatibiapalpus by Gabriel and Sherwood [4]. In the same work, Gabriel and Sherwood [4] considered P. trinitatis pauciaculeis to be a junior synonym of $S$. trinitatis based on the near-identical morphology of the male palpal bulb, tibial apophysis and palpal tibial apophysis. This resolved the placement of the subspecies shortly after it was preliminarily considered a subspecies inquirenda by Nentwig et al. [13] whose important work served to stabilise the taxonomy of a significant number of subspecific taxa described by Embrik Strand (1876-1947) during the late nineteenth and early twentieth century. Many (but not all) of Strand's type specimens from 1906-1917 deposited in German museums were destroyed during RAF bombing raids in the Second World War.

Despite the recent redescription of $S$. trinitatis, the female of this species was still unknown. Recently, JPLG contacted DS and RG regarding four female specimens which he had provisionally identified several years earlier as a potentially undescribed species of Ami Pérez-Miles, 2008 [14] (now Neischnocolus Petrunkevitch, 1925 [15] per Pérez-Miles, Gabriel and Sherwood [16]) in his joint work on another Trinidadian theraphosid spider, 
Neoholothele incei (F. O. Pickard-Cambridge, 1899) [17] (see Guadanucci and Weinmann [18]). JPLG had since noticed the specimens may be more congruently placed in the genus Spinosatibiapalpus. Based on this useful information, DS was able to examine these specimens, held in the Natural History Museum, London, in October 2021 and determined they were indeed Spinosatibiapalpus specimens, based on the medium quantity of labial cuspules and presence of Type I urticating setae in conjunction with their small body size. Furthermore, the general morphology of the spermathecae was superficially similar to that of the prior-known female of S. spinulopalpus. We also additionally had the opportunity to compare this material against photographs of two more recent preserved specimens of $S$. trinitatis, allowing us to confirm, based on spermathecal morphology and body size, that the paralectotype females of $N$. incei can indeed be considered conspecific with S. trinitatis.

In this work, we are thus able to describe the female of $S$. trinitatis for the first time, thereby providing additional and novel data for this taxon.

\section{Materials and Methods}

Specimens were examined under binocular microscopes. Photographs of spermathecae were made using a Canon EOS 6D Mark II attached to a Leica MZ12.5 with images stacked using Helicon Focus software. Description style follows Sherwood et al. [19]. Abbreviations, Institutes: BMNH = Natural History Museum, London, United Kingdom; SMF = Senckenberg Forschungsinstitut und Naturmuseum, Frankfurt am Main, Germany. Structures: ALE = anterior lateral eyes, $\mathrm{AME}=$ anterior median eyes, GP = guard plates (of spermathecae sensu Gabriel and Sherwood [4]), PLE = posterior lateral eyes, $\mathrm{PME}=$ posterior median eyes. Other: coll. $=$ collector; colln. $=$ collection; det. = determined by. Abbreviations for museum collections follow Evenhuis [20]. Leg spine terminology follows Petrunkevitch [15] with the modifications proposed by Bertani [21]: $\mathrm{d}=$ dorsal, $\mathrm{v}=$ ventral, $\mathrm{r}=$ retrolateral, $\mathrm{p}=$ prolateral. Leg formulae start with the longest leg to the shortest in order of decreasing size, e.g., 4, 1, 2, 3. Urticating setae terminology follows Cooke, Roth and Miller [22]. Palpal bulb morphology follows Bertani [23] with the modifications outlined in Gabriel and Sherwood [4]. All measurements are in mm. Authors' emphases in [ ].

\section{Results}

Spinosatibiapalpus trinitatis (Pocock, 1903)

Metriopelma trinitatis Pocock, 1903: 114.

Crypsidromus trinitatis: Petrunkevitch, 1911: 56.

Crypsidromus trinitatis pauciaculeis Strand, 1916: 85.

Pseudhapalopus trinitatis: Gabriel, 2016: 87.

Pseudhapalopus trinitatis pauciaculeis: Gabriel, 2016: 87.

Pseudhapalopus trinitatis pauciaculeis: Nentwig et al., 2019: 45. (subspecies inquirenda)

Spinosatibiapalpus trinitatis: Gabriel and Sherwood, 2020: 311, figs. 35-41.

LSID: [urn:lsid:nmbe.ch:spidersp:002215]

Type material: Holotype o Metriopelma trinitatis (BMNH 1901.8.1.7), Trinidad, coll. W. Ince, examined; holotype o Crypsidromus trinitatis pauciaculeis (SMF 2669), Mittel-Südamerika, Trinidad und Tobago, Trinidad, Gerold leg. 1888, E. Strand det., examined; paralectotypes 4 o 9 Neoholothele incei [not conspecific to lectotype] (BMNH 1898.4.2.56-63), Trinidad, coll. W. Ince, examined.

Diagnosis: (modified from Gabriel and Sherwood [4]) S. trinitatis can be distinguished from males of S. spinulopalpus by the absence of a tibial apophysis (tibial apophysis present in S. spinulopalpus), from S. tansleyi by the PI longer than the PS (PS longer than PI in S. tansleyi) and further by its smaller body size (known total length $\leq 25.0$ vs. 38.0 in holotype of S. tansleyi), and from S. bora by the weakly developed PI (PI developed in S. bora), comparatively less distinct PAR (PAR comparatively more distinct in S. bora), PI longer than PS (PS and PI of approximately equal length in S. bora), and by the increased number of spines on the palpal tibia (>20 vs. 8 in S. bora). Females of S. trinitatis can be 
distinguished from S. spinulopalpus by the straighter spermathecal receptacles (Figure 1) (spermathecal receptacles strongly curved retrolaterally in S. spinulopalpus, see Gabriel and Sherwood [4]). The females of S. bora and S. tansleyi are unknown.
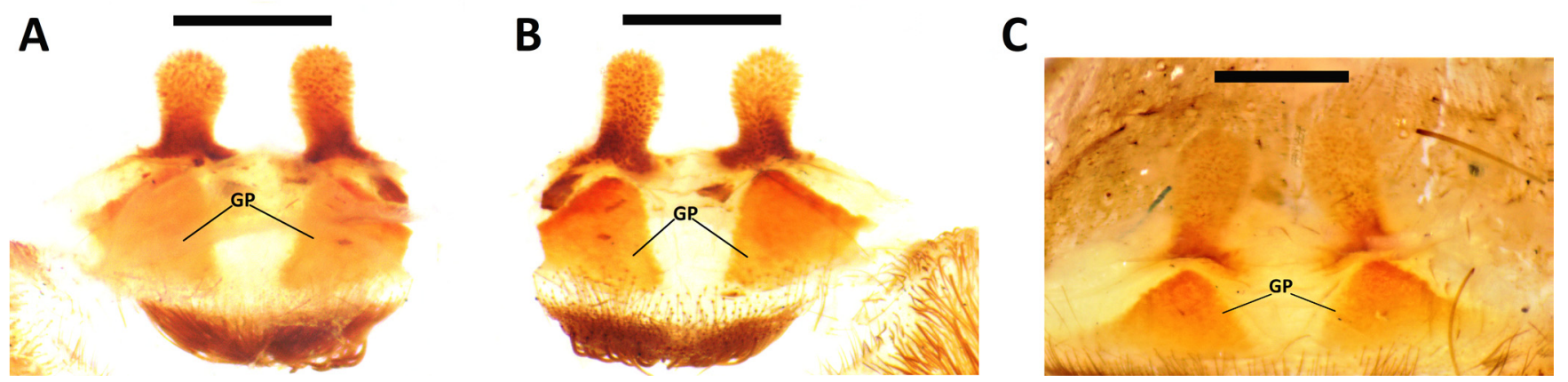

Figure 1. Spinosatibiapalpus trinitatis female spermathecae, (A) paralectotype female 1 of $N$. incei [not conspecific to lectotype], (BMNH 1898.4.2.56-63), dorsal view; (B) paralectotype female 1 of $N$. incei [not conspecific to lectotype], (BMNH 1898.4.2.56-63), ventral view; (C) non-type female (BMNH 1893.11.2.4), dorsal view. Scale bars $=1 \mathrm{~mm}$.

Male: See Gabriel and Sherwood [4] (pp. 311-312, figs. 35-41).

Description of female: Paralectotype female 1 of $N$. incei [not conspecific to lectotype] (BMNH 1898.4.2.56-63): Total length including chelicerae: 21.7. Carapace: length 8.9, width 6.6. Caput: raised. Ocular tubercle: raised, length 0.5, width 1.4. Eyes: ALE > AME, AME > PLE, PLE > PME, anterior row procurved, posterior row recurved. Clypeus: narrow; clypeal fringe: long. Fovea: deep, slightly recurved. Chelicera: length 5.0, width 1.8. Abdomen: (damaged) length 7.8, width 3.5. Maxilla with 70-80 cuspules, covering approximately $37 \%$ of proximal edge. Labium: length 0.8 , width 1.2 , with $15-20$ labial cuspules most separated by $0.5-1.0 \times$ the width of a single cuspule. Labio-sternal mounds: joined. Sternum: (damaged) length 3.7, width 3.6, with three pairs of sigilla. Tarsi II-IV divided by band of setae (tarsus I missing but presumably also divided by band of setae as in all other specimens examined for this work). Metatarsal scopulae: I (unable to measure as segment missing); II 83\%; III 27\%; IV ascopulate. Lengths of leg and palpal segments: see Table 1. Spination: (except tibia I and metatarsus I which are missing) femur III d $0-0-2$, patella III p $0-0-1, \mathrm{r} 0-0-1$, tibia II $\mathrm{v} 0-1-2$ (apical), p $1-1-1$, III $1-0-2$ (apical), $\mathrm{p}$ $0-1-3$, r 1-1-1, IV v 1-2-3 (apical), p 1-2-1, r 2-2-2, palp v 0-0-1, p 0-0-2, metatarsus II v 2-0-3 (apical), p 1-0-1, III v 8-2-3 (apical), p 1-1-2, r 1-0-0, IV d 1-0-2, v 1-2-6 (4 apical), p 1-2-1, r 2-2-2. Posterior lateral spinnerets with three segments: basal 1.3, medial 0.9, digitiform apical 1.3. Posterior median spinnerets with one segment. Spermathecae with two divergent receptacles emerging from a single wide base, GP sclerotised, receptacles generally straight. (Figure 1). Urticating setae: Type I present dorsally. Colour: alcohol preserved brown.

Table 1. Spinosatibiapalpus trinitatis non-type female (paralectotype female 1 of $N$. incei [not conspecific to lectotype]) (BMNH 1898.4.2.56-63), podomere lengths * indicates segments missing.

\begin{tabular}{cccccc}
\hline & I & II & III & IV & Palp \\
\hline Femur & 6.1 & 5.1 & 4.5 & 6.4 & 4.6 \\
Patella & 3.3 & 3.3 & 2.6 & 3.2 & 2.5 \\
Tibia & $*$ & 3.5 & 3.6 & 4.7 & 3.2 \\
Metatarsus & $*$ & 3.3 & 3.6 & 6.3 & - \\
Tarsus & $*$ & 2.5 & 2.5 & 2.6 & 3.1 \\
Total & $*$ & 17.7 & 16.8 & 23.2 & 13.4 \\
\hline
\end{tabular}

Variation: Paralectotype female 2 of $N$. incei [not conspecific to lectotype] (BMNH 1898.4.2.56-63): Total length including chelicerae: 21.7. Carapace: length 7.9, width 6.1. 
Ocular tubercle: length 0.7, width 1.4. Eyes: ALE > AME, AME > PLE, PLE > PME. Chelicera length 5.0, width 2.0. Abdomen: length 8.8, width 4.7. Maxilla: with 40-50 cuspules, covering approximately $45 \%$ of proximal edge. Labium: length 0.8 , width 1.3 , with 30-35 labial cuspules. Sternum: length 3.3, width 3.0. Metatarsal scopulae: I 100\%; II 82\%; III 25\%; IV ascopulate. Lengths of leg and palpal segments see Table 2, legs 4, 1, 3, 2. Spination: femur III d 0-0-2, IV d 0-0-1, tibia II v 0-1-0, p 1-1-1, III v 0-1-2 (apical), p 1-1-1, r 1-1-1, IV v 1-0-3 (apical), p 1-1-1, r 1-2-1, palp v 0-0-2, p 0-0-1, metatarsus I v 0-1-2 (apical), II v 0-1-2 (apical), p 0-1-2, III v 2-2-4 (apical), p 0-2-2, r 3-1-3, IV v $3-2-5$ (4 apical), p 3-2-2, r 2-2-3. Posterior lateral spinnerets with three segments: basal 1.4, median 1.0, digitiform apical 1.2.

Table 2. Spinosatibiapalpus trinitatis non-type female (paralectotype female 2 of $N$. incei [not conspecific to lectotype]) (BMNH 1898.4.2.56-63), podomere lengths.

\begin{tabular}{cccccc}
\hline & I & II & III & IV & Palp \\
\hline Femur & 4.8 & 3.6 & 3.7 & 4.6 & 3.3 \\
Patella & 3.3 & 2.8 & 2.5 & 2.8 & 2.2 \\
Tibia & 3.7 & 3.1 & 2.9 & 4.0 & 2.8 \\
Metatarsus & 2.9 & 2.7 & 2.9 & 5.2 & - \\
Tarsus & 2.6 & 2.3 & 2.3 & 2.3 & 2.4 \\
Total & 17.3 & 14.5 & 14.3 & 18.9 & 10.7 \\
\hline
\end{tabular}

Paralectotype female 3 of $N$. incei [not conspecific to lectotype] (BMNH 1898.4.2.56-63): Total length including chelicerae: 17.6. Carapace: length 7.5, width 5.8. Ocular tubercle: length 0.7, width 1.2. Eyes: AME > ALE, ALE > PLE, PLE $>$ PME. Chelicera length 3.3, width 1.9. Abdomen: length 6.8 , width 5.0. Maxilla: with 50-60 cuspules, covering approximately $57 \%$ of proximal edge. Labium: length 0.9 , width 1.1 , with $30-35$ labial cuspules. Sternum: length 2.9, width 2.8. Metatarsal scopulae: I 95\%; II 80\%; III 36\%; IV (unable to measure as a particular leg IV matching the specimen could not be definitively associated, but presumably absent as in all other specimens examined for this work). Lengths of leg and palpal segments see Table 3. Spination: (except leg IV) femur III d $0-0-1$, patella III r $0-2-0$, tibia v $0-1-3$ (apical), p $0-1-0$, r $2-2-1$, II p $0-0-2$, III p $0-1-0$, r $0-4-1$, metatarsus I v $0-1-2$ (apical), II v 0-0-2 (apical), p 0-0-2, III v 2-2-3 (apical), p 0-1-1, r 3-1-1. Posterior lateral spinnerets with three segments: basal 1.0, median 0.7, digitiform apical 1.1.

Table 3. Spinosatibiapalpus trinitatis non-type female (paralectotype female 3 of $N$. incei [not conspecific to lectotype]) (BMNH 1898.4.2.56-63), podomere lengths * indicates segments missing.

\begin{tabular}{cccccc}
\hline & I & II & III & IV & Palp \\
\hline Femur & 5.0 & 4.5 & 4.3 & $*$ & 3.9 \\
Patella & 3.1 & 2.5 & 2.3 & $*$ & 2.1 \\
Tibia & 3.4 & 2.8 & 2.6 & $*$ & 2.6 \\
Metatarsus & 2.7 & 2.5 & 3.2 & $*$ & - \\
Tarsus & 1.8 & 1.9 & 2.1 & $*$ & 2.3 \\
Total & 16.0 & 14.2 & 14.5 & $*$ & 10.9 \\
\hline
\end{tabular}

Paralectotype female 4 of $N$. incei [not conspecific to lectotype] (BMNH 1898.4.2.56-63): Total length including chelicerae: 21.9. Carapace: length 8.9, width 6.2. Ocular tubercle: length 0.8, width 1.5. Eyes: ALE > AME, AME > PLE, PLE > PME. Chelicera length 4.0, width 2.1. Abdomen: length 9.0, width 6.2. Maxilla: with 60-70 cuspules, covering approximately $50 \%$ of proximal edge. Labium: length 0.9 , width 1.6 , with $15-20$ labial cuspules. Sternum: length 3.4, width 3.2. Metatarsal scopulae: I 96\%; II 80\%; III 22\%; IV ascopulate. Lengths of leg and palpal segments see Table 4, legs 4,1,3,2. Spination: femur III d $0-0-1$, patella III p $0-0-1$, r $0-0-1$, tibia II $\vee 0-1-0$, p $0-0-2$, III $0-2-3$ (apical), p $1-1-1$, r 1-1-1, IV v 2-1-3 (apical), p 1-1-1, r 1-2-1, palp v 0-0-2, p 0-2-1, metatarsus I v $1-0-2$ 
(apical), II v 0-2-3 (apical), p 1-1-1, III v 0-2-4 (3 apical), p 1-2-1, r 0-1-1, IV v 2-3-6 (3 apical), p 1-1-1, r 1-1-2. Posterior lateral spinnerets with three segments: basal 1.3, median 1.0, digitiform apical 1.3.

Table 4. Spinosatibiapalpus trinitatis non-type female (paralectotype female 4 of $N$. incei [not conspecific to lectotype]) (BMNH 1898.4.2.56-63), podomere lengths.

\begin{tabular}{cccccc}
\hline & I & II & III & IV & Palp \\
\hline Femur & 5.2 & 4.8 & 4.7 & 6.0 & 4.2 \\
Patella & 3.6 & 3.0 & 2.7 & 3.0 & 2.6 \\
Tibia & 4.1 & 3.0 & 2.7 & 4.5 & 3.1 \\
Metatarsus & 3.3 & 3.2 & 3.7 & 5.1 & - \\
Tarsus & 2.4 & 2.3 & 2.2 & 2.5 & 2.5 \\
Total & 18.6 & 16.3 & 16.0 & 21.1 & 12.4 \\
\hline
\end{tabular}

Other material examined: $4 \sigma^{x} \sigma^{x}, 1$ unknown [sex indeterminable] BMNH 1933.12.20.16 (part), Trinidad, B.W.I., August-September 1926, coll J.S. Dunkerley; 1 o(BMNH 1893.11.2.4), Trinidad, Beaven Rake Esq., 'Hapalopus incei', Spinosatibiapalpus trinitatis det. D. Sherwood 19 October 2021.

Distribution: Trinidad (see Sherwood and Gabriel [2] for map of the distribution of all presently known Spinosatibiapalpus species).

Remarks: The paralectotype females of $N$. incei (numbered herein 1-4 to allow ease of reference by future workers) are fragmented. Paralectotype 1 is the specimen from which the spermathecae was dissected by a previous worker. All specimens have legs detached from the body and, in some cases, certain legs are missing entirely. Some additional legs and leg segments were found mixed in the tube which contains the lectotype male of $N$. incei and another male of that taxon (thereby a paralectotype but not mentioned as such in Guadanucci and Weinmann [18]) but none of the extra legs could be matched unequivocally to any particular female of $S$. trinitatis. Therefore, we only included data for legs found in the tube which contained the females, and which could be definitively associated with a particular specimen. Some of the extra legs found loose in the tube with the males of $N$. incei are considerably larger than the other legs that could be associated with the four $S$. trinitatis specimens. Thus, they may be from an entirely different specimen (or specimens) altogether, no longer present in the sample. This possibility is further supported by the fact the accession number accounts for 8 specimens but only 6 (two males of $N$. incei sensu stricto and four females of $S$. trinitatis) were found to be present in the tubes in the jar. Pickard-Cambridge [17] (p. 895) states that Mr. Ince collected "four males and several females" thereby not specifying the precise number of females that he received from Ince. The two other males mentioned by Pickard-Cambridge [17] are not present in the jar and are probably lost, but the extra leg segments in the jar with the two present males of $N$. incei are far too large to be from other males of this species and thus must originate from some other specimen(s), possibly even a species unrelated to the other two taxa found in the sample. All specimens and parts of specimens found still associated with the tubes in the original jar were recurated by DS during the course of this work.

Whilst examining the above type material DS decided to check other historical specimens in the BMNH collection and located a jar containing a single female theraphosine labelled as "Hapalopus incei" from Trinidad collected by Beaven Neave Rake (1866-1922). Pickard-Cambridge [17] (p. 895) mentions additional, non-type, material collected by Beaven Rake and Thomas Potter (these two collectors operated individually from each other) which he considered conspecific with N. incei (as H. incei) and presumably this specimen is one of those additional "examples" from Rake mentioned by Pickard-Cambridge [17]. This specimen was found to share all the secondary taxonomic characters (see introduction) found in the paralectotypes of $N$. incei and dissection of the spermathecae confirmed the specimen to indeed be $S$. trinitatis (Figure 1C). 


\section{Discussion}

Comparison of historical material against more recently collected material, where possible, is valuable for taxonomic works. We were recently able to view photographs from a colleague of two more recently preserved specimens (one male and one female) of S. trinitatis collected $2 \mathrm{~km}$ north of Port of Spain. The morphology of the male palpal bulb is congruent with that of the holotype of $S$. trinitatis, confirming the identity of these specimens and allowing us to compare the paralectotype series of $N$. incei against a more recently collected female. The female shared the characters mentioned above for the paralectotype series of $N$. incei, especially the morphology of the spermathecae, supporting the conclusion that the paralectotype females of $N$. incei can indeed be considered conspecific with the holotype male of $S$. trinitatis. We can also therefore solidify the presence of $S$. trinitatis on the island of Trinidad and indicate a more precise distribution, which at the very least encompasses an area in the north of the island, close to the capital.

The distribution of the congeneric $S$. tansleyi still needs clarification, and its location of "west-central Trinidad" may not necessarily refer to the island of Trinidad (see Gabriel and Sherwood [4]). Additionally, the females of S. trinitatis examined for this work are all $>15 \mathrm{~mm}$ smaller in body length in comparison to that of the holotype male of $S$. tansleyi. This, in our opinion, also makes conspecifity very unlikely. We have now directly examined and measured a total of 12 specimens of $S$. trinitatis in museum collections (6 males, 5 females and one specimen of indeterminate sex) and have observed low intrasexual and intraspecific variation in body size, with no overlap in either sex with that of the holotype male of S. tansleyi.

Author Contributions: Conceptualization, D.S. and J.P.L.G.; methodology, D.S., J.P.L.G. and R.G.; investigation, D.S., J.P.L.G. and R.G.; writing—original draft preparation, D.S.; writing—review and editing, D.S., J.P.L.G. and R.G.; visualization, D.S.; project administration, D.S. All authors have read and agreed to the published version of the manuscript.

Funding: This research received no external funding.

Institutional Review Board Statement: Not applicable.

Informed Consent Statement: Not applicable.

Data Availability Statement: Not applicable.

Acknowledgments: We would like to thank Jan Beccaloni (BMNH), and Peter Jäger and Julia Altmann (SMF) for access to the museums and loan of specimens. D.S. thanks Richard Turney (BMNH) for allowing use of the facilities in the Sackler Biodiversity Imaging Laboratory. We also thank three anonymous reviewers whose comments improved the manuscript.

Conflicts of Interest: The authors declare no conflict of interest.

\section{References}

1. World Spider Catalog. The World Spider Catalog, Version 22.5; Naturhistorisches Museum Bern: Bern, Switzerland, 2021; Available online: http:/ /wsc.nmbe.ch (accessed on 24 December 2021).

2. Sherwood, D.; Gabriel, R. A new species of Spinosatibiapalpus Gabriel \& Sherwood from Peru (Araneae: Theraphosidae). Rev. Ibérica Aracnol. 2021, 38, 87-91.

3. Schmidt, G.; Weinmann, D. Eine neue Pseudhapalopus-Art aus Kolumbien (Arachnida: Araneae: Theraphosidae: Theraphosinae). Entomol. Z. 1997, 107, 69-72.

4. Gabriel, R.; Sherwood, D. Revised taxonomic placement of Pseudhapalopus Strand, 1907, with notes on some related taxa (Araneae: Theraphosidae). Arachnology 2020, 18, 301-316. [CrossRef]

5. Pocock, R.I. On some genera and species of South-American Aviculariidae. Ann. Mag. Nat. Hist. 1903, 11, 81-115. [CrossRef]

6. Petrunkevitch, A. A synonymic index-catalogue of spiders of North, Central and South America with all adjacent islands, Greenland, Bermuda, West Indies, Terra del Fuego, Galapagos, etc. Bull. Am. Mus. Nat. Hist. 1911, $29,1-791$.

7. Ausserer, A. Beiträge zur Kenntniss der Arachniden-Familie der Territelariae Thorell (Mygalidae Autor). Verh. Kais.-K. Zool.-Bot. Ges. Wien 1871, 21, 117-224.

8. Simon, E. Histoire Naturelle des Araignées, Tome A; Roret: Paris, France, 1892; pp. 1-256.

9. Becker, L. Diagnoses de quelques aranéides nouvelles du Mexique. Ann. Soc. Entomol. Belg. 1878, 21, 77-80. 
10. Strand, E. Systematische-faunistische Studien über paläarktische, afrikanische und amerikanische Spinnen des Senckenbergischen Museums. Arch. Nat. 1916, 81, 1-153.

11. Gabriel, R. Revised taxonomic placement of the species in the Central American genera Davus O. Pickard-Cambridge, 1892, Metriopelma Becker, 1878, and Schizopelma F. O. Pickard-Cambridge, 1897, with comments on species in related genera (Araneae: Theraphosidae). Arachnology 2016, 17, 61-92. [CrossRef]

12. Strand, E. Vorläufige Diagnosen afrikanischer und südamerikanischer Spinnen. Zool. Anz. 1907, 31, 525-558.

13. Nentwig, W.; Blick, T.; Gloor, D.; Jäger, P.; Kropf, C. Tackling taxonomic redundancy in spiders: The infraspecific spider taxa described by Embrik Strand (Arachnida: Araneae). Arachnol. Mitt. 2019, 58, 29-51. [CrossRef]

14. Pérez-Miles, F.; Gabriel, R.; Miglio, L.; Bonaldo, A.; Gallon, R.; Jimenez, J.J.; Bertani, R. Ami, a new theraphosid genus from Central and South America, with the description of six new species (Araneae: Mygalomorphae). Zootaxa 2008, 1915, 54-68. [CrossRef]

15. Petrunkevitch, A. Arachnida from Panama. Trans. Conn. Acad. Arts Sci. 1925, 27, 51-248.

16. Pérez-Miles, F.; Gabriel, R.; Sherwood, D. Neischnocolus Petrunkevitch, 1925, senior synonym of Ami Pérez-Miles, 2008 and Barropelma Chamberlin, 1940 (Araneae: Theraphosidae). Arachnology 2019, 18, 150-155. [CrossRef]

17. Pickard-Cambridge, F.O. On new species of spiders from Trinidad, West Indies. Proc. Zool. Soc. Lond. 1899, 66, 890-900. [CrossRef]

18. Guadanucci, J.P.L.; Weinmann, D. Description of Neoholothele gen. nov. (Araneae, Theraphosidae, Schismatothelinae). Stud. Neotrop. Fauna Environ. 2015, 50, 221-228. [CrossRef]

19. Sherwood, D.; Fabiano-da-Silva, W.; Gabriel, R.; Lucas, S.M. Redescription of Nesipelma insulare Schmidt \& Kovařík, 1996 with a revised generic diagnosis for Nesipelma Schmidt \& Kovařík, 1996 and a transfer from Cyrtopholis Simon, 1892 (Araneae: Theraphosidae). Arachnology 2020, 18, 462-467.

20. Evenhuis, N.L. The Insect and Spider Collections of the World; Bishop Museum: Honolulu, HI, USA, 1997; Available online: http:/ /hbs.bishopmuseum.org/codens (accessed on 24 December 2021).

21. Bertani, R. Revision, cladistic analysis, and zoogeography of Vitalius, Nhandu, and Proshapalopus; with notes on other theraphosine genera (Araneae, Theraphosidae). Arq. Zool. 2001, 36, 265-356.

22. Cooke, J.A.L.; Roth, V.D.; Miller, F.H. The urticating hairs of theraphosid spiders. Am. Mus. Novit. 1972, 2498, 1-43.

23. Bertani, R. Male palpal bulbs and homologous features in Theraphosinae (Araneae, Theraphosidae). J. Arachnol. 2000, 28, 29-42. [CrossRef] 